\title{
Association between salt substitutes/enhancers and changes in sodium levels in fast-food restaurants: a cross-sectional analysis
}

\author{
Mary J. Scourboutakos PhD, Sarah A. Murphy BSc, Mary R. L’Abbé PhD
}

\section{Abstract}

Background: Restaurant foods have high sodium levels, and efforts have been made to promote reductions. The objective of this study was to understand if salt substitutes and enhancers are associated with changes in sodium levels in fast-food restaurants.

Methods: A longitudinal database (MENU-FLIP) containing nutrition information for Canadian chain restaurants with 20 or more locations nationally was created in 2010 and updated in 2013 and 2016. In 2016, when available, ingredient lists were collected from restaurant websites and searched for the presence of salt substitutes/enhancers. Changes in sodium levels (per serving) and the prevalence of salt substitutes/enhancers in 222 foods from 12 of the leading fast-food restaurant chains were compared across 3 time points.

Results: Sixty-nine percent of foods contained a salt substitute/enhancer. Substitutes/enhancers were found in every restaurant chain $(n=12)$ for which ingredient data were available. The most common substitutes/enhancers were yeast extracts (in $30 \%$ of foods), calcium chloride (28\%), monosodium glutamate (14\%) and potassium chloride (12\%). Sodium levels in foods that contained substitutes/enhancers decreased significantly more $(190 \pm 42 \mathrm{mg} / \mathrm{serving})$ over the study period than those in foods that did not contain a substitute/enhancer $(40 \pm 17 \mathrm{mg} /$ serving, $p<0.001)$.

Interpretation: Salt substitutes and enhancers are prevalent in restaurant foods and are one means by which restaurants may be lowering sodium levels in their foods. At this time, the potential consequences of these findings, if any, are uncertain.

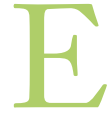
xcessive dietary sodium intake is a causal risk factor for hypertension, ${ }^{1}$ which is the leading preventable risk factor for death worldwide. ${ }^{2}$ Research has shown that $72 \%$ of dietary sodium comes from food obtained at restaurants. ${ }^{3}$ This is partly due to the increased prevalence of eating outside the home, ${ }^{4-8}$ along with the excessive sodium levels commonly found in restaurant foods. ${ }^{9-11}$ It has been recommended that the best strategy to lower sodium intake is to gradually reduce levels across the food supply to enable consumers' taste buds to become accustomed to less salt. ${ }^{12-14}$ Salt substitutes (such as potassium chloride) and salt enhancers (such as monosodium glutamate [MSG] and yeast extracts) are one means by which sodium can be removed from food without reducing its perceived salty taste. ${ }^{12,15,16}$ The market share for salt enhancers such as MSG, yeast extracts and hydrolyzed vegetable proteins is on the rise. ${ }^{17}$ Food manufacturers find MSG desirable because it stimulates the fifth taste: umami. ${ }^{18}$ Furthermore, when compared with table salt, MSG contains one-third the amount of sodium, thus enabling manufacturers to reduce sodium by as much as $40 \%$, with no loss of palatability. ${ }^{16,19}$ However,
MSG has been a controversial ingredient since $1968 .{ }^{20}$ MSG is believed to elicit symptoms because of the free (unbound) glutamate that it contains. Studies have investigated the effect of MSG on a variety of symptoms (including headache, nausea, flushing, dizziness, burning, perspiration, chest pain/pressure, muscle pain and insulin secretion), with mixed results. ${ }^{21-34}$ The inconsistency of the findings is probably due to the fact that many early studies were anecdotal, ${ }^{20,35,36}$ had small sample sizes, ${ }^{21,22,26,27,31}$ tested a wide range of doses (varying from 1.25 to $10 \mathrm{~g}$ ), ${ }^{23,34}$ administered MSG in a variety of food contexts (e.g., non-caloric beverages versus whole meals), ${ }^{21,22,28,30,37-39}$ and were confounded by the fact that some individuals are sensitive to MSG while others are

Competing interests: None declared.

This article has been peer reviewed.

Correspondence to: Mary L'Abbé, mary.labbe @utoronto.ca

CMAJ Open 2018. DOI:10.9778/cmajo.20170137 
not. ${ }^{23,25,27,29,34}$ The first objective of this study was to investigate the prevalence of salt substitutes/enhancers in restaurant foods. The second objective was to understand if there is an association between the presence of a salt substitute/ enhancer in a food and the magnitude of decrease in the sodium level of that food between 2010 and 2016. The third objective was to determine if the presence of glutamate-containing enhancers (MSG, yeast extracts and hydrolyzed vegetable proteins) is associated with decreased sodium levels in restaurant foods between 2010 and 2016.

\section{Methods}

Data for this study were derived from the University of Torronto's MENU-FLIP database of restaurant nutrition. This study was the third in a series of studies investigating changes in sodium levels in Canadian chain restaurant foods. First, a baseline analysis of sodium levels in restaurant foods in 2010 was published. ${ }^{40}$ Three years later a longitudinal follow-up was conducted to investigate changes in sodium levels between 2010 and $2013 .{ }^{41}$

\section{Data collection}

In 2010, MENU-FLIP was created using publicly available nutrition information provided online by all chain restaurants that had 20 or more locations nationally. ${ }^{42}$ According to the 2010 Directory of Restaurant and Fast-Food Chains in Canada, 172 restaurants had at least 20 locations nationally. ${ }^{43}$ A website search revealed that 95 of these restaurants provided nutrition information online; data were extracted by a single researcher. Data for over 9000 à la carte entrées, side dishes, beverages and condiments were collected and compiled into the database (Figure 1). Foods were categorized according to the restaurant (e.g., McDonald's, Subway; subsequently referred to as the restaurant variable), the type of restaurant (fast food v. sit down), the type of food (e.g., hamburger, sandwich, chicken, french fries; subsequently referred to as the food category variable) and the type of food item (e.g., entrée, side dish, kids' item). Additional details about the database can be found elsewhere. ${ }^{42}$

In 2010, 4044 entrées, side dishes and kids' meals were analyzed in the baseline report. ${ }^{40}$ In May 2013, restaurant websites were revisited and data were recollected. ${ }^{37}$ When

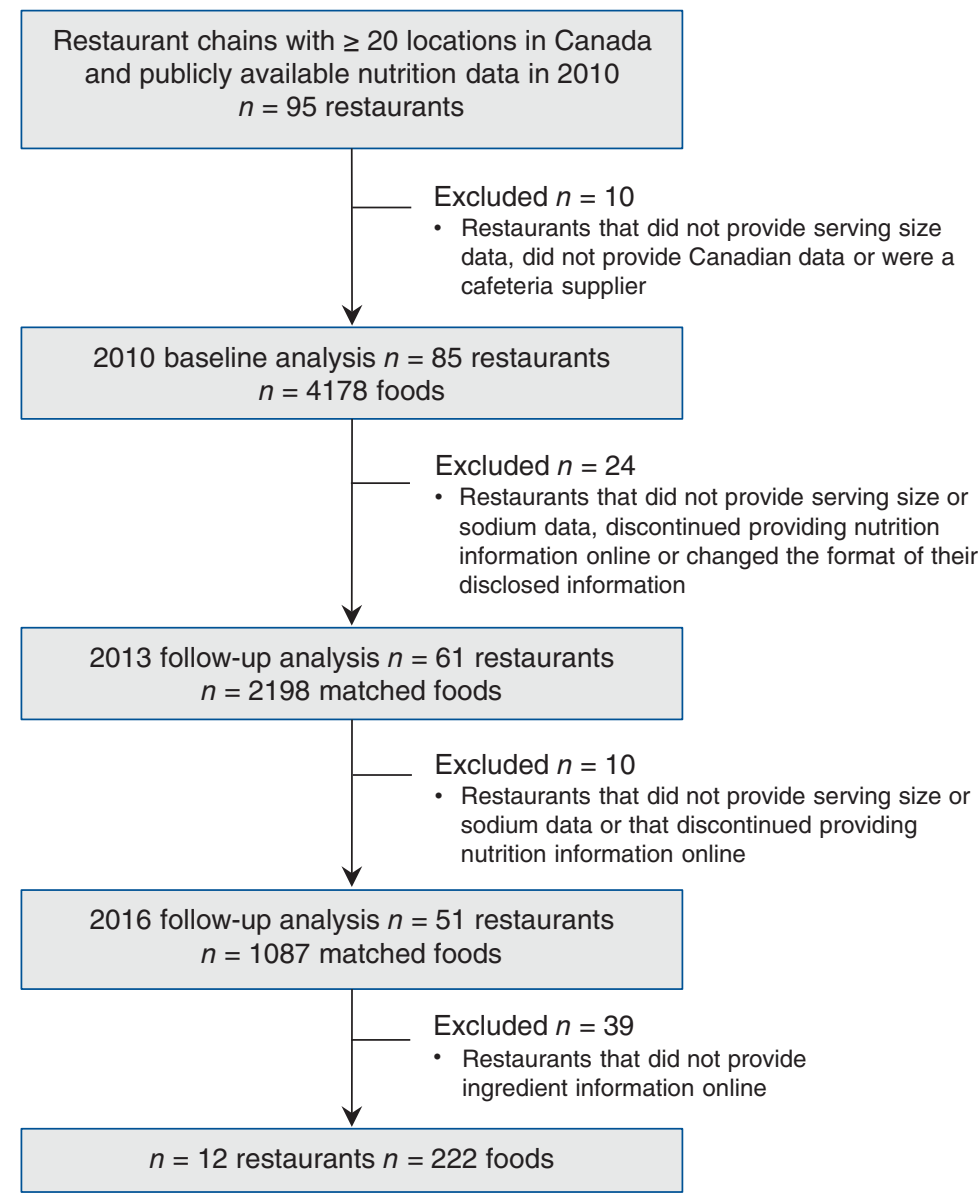

Figure 1: Identification of foods and restaurants meeting inclusion criteria. 
available, the updated nutrient information collected in 2013 was matched with the product data from 2010. In 2013, we were able to match data for 2198 foods across the 2 time points. When previous data had not been collected for a particular food item, the food was labelled as being a new product. In May 2016, this process was repeated. Data collected in 2016 were entered and matched with those for foods in 2010 and 2013 by one author (SAM). Another author (MJS) double-checked data entry and matches. In addition, range and logic checks were conducted and $10 \%$ of the data set was verified against the original source by a third-party data checker.

After sodium levels (per serving) in 2016 were subtracted from sodium levels (per serving) in 2010, foods were coded as having increased, decreased or stayed the same. This coding was subsequently converted into a binary "decrease versus did not decrease" variable that distinguished between foods whose sodium level decreased and those whose sodium level did not decrease (increased or stayed the same). Among foods whose sodium level decreased, a numerical "magnitude of decrease" variable was calculated by subtracting 2010 sodium levels (per serving) from 2016 levels.

Ingredient information was collected from restaurant websites in 2016. The list of salt substitutes/enhancers in Appendix D of the Institute of Medicine's Strategies to Reduce Sodium Intake in the United States was used to identify potential substitutes/enhancers. ${ }^{12}$ Ingredient lists were searched for all substitutes/enhancers listed in the report (Appendix 1, Supplemental Table 1, available at www.cmajopen.ca/content/6/1/E118/ suppl/DC1). When a food contained a salt substitute/ enhancer, this information was entered into the MENUFLIP database. The presence of each salt substitute/enhancer in a given food was coded separately as a binary (yes/no) variable. Two additional aggregate variables were also created: salt substitute/enhancer (a binary yes/no variable to indicate whether a given food contained any salt substitute/enhancer) and glutamate-containing enhancers (a binary yes/no variable to indicate whether a given food contained monosodium glutamate and/or hydrolyzed vegetable protein and/or yeast extracts). According to the aforementioned Institute of Medicine report, hydrolyzed vegetable protein and yeast extracts "often contain MSG."12 A complete list of ingredient names that were considered to potentially contain MSG can be found in Appendix 1. ${ }^{12,44,45}$ The glutamate-containing enhancers variable enabled us to assess the prevalence of glutamatecontaining enhancers; we investigated this because glutamate is the active component in these enhancers that has been mechanistically linked with symptoms such as headache and muscle pain. ${ }^{21,46-48}$

\section{Inclusion and exclusion criteria}

The following foods were excluded from this analysis: foods that are not a major source of dietary sodium (beverages, baked goods, desserts and ice cream), appetizers (because portion sizes varied widely from 2 to 10 servings), sauces and condiments (because they were not consistently reported), meals that reported data for entrées in combination with side dishes (only individual, à la carte menu items were analyzed), foods for which serving size or sodium information was unavailable, size duplications, and foods in categories that had fewer than 10 items. Sit-down restaurants were excluded because those that met the study criteria did not provide complete ingredient information and therefore data from these restaurants could not be analyzed.

\section{Statistical analysis}

The proportion of foods that contained any substitute/ enhancer, each substitute/enhancer and glutamate-containing enhancers was tabulated and stratified across foods whose levels of the substitutes/enhancers decreased versus those whose levels did not decrease between 2010 and 2016.

$\chi^{2}$ tests were used to assess the association between the presence of a salt substitute/enhancer in a food and whether that food's sodium content ( $\mathrm{mg} / \mathrm{serving}$ ) decreased over the study period (the "decrease versus did not decrease" variable). This test was repeated for each substitute/enhancer and for the glutamate-containing enhancers variable.

For the subset of foods whose sodium level decreased, the non-parametric Wilcoxon signed-rank test was used to compare the median magnitude of decrease in foods that contained a salt substitute/enhancer with that in foods that did not contain a salt substitute/enhancer. Comparisons of the magnitude of decrease were computed overall and were stratified by food category.

All statistical analyses were conducted using SAS version 9.3 software (SAS Institute Inc.).

\section{Ethics approval}

This study was not required to undergo review by the Health Sciences Research Ethics Board at the University of Toronto because the research did not involve human subjects.

\begin{tabular}{|c|c|c|}
\hline $\begin{array}{l}\text { Restaurant } \\
\text { chain }\end{array}$ & $\begin{array}{l}\text { No. of outlets } \\
\text { (as of 2016) }\end{array}$ & $\begin{array}{l}\text { No. of foods } \\
\text { represented in the } \\
\text { sample }\end{array}$ \\
\hline$A \& W$ & 820 & 30 \\
\hline Arby's & $53^{*}$ & 24 \\
\hline Burger King & 291 & 44 \\
\hline Edo Japan & 106 & 18 \\
\hline KFC & 638 & 19 \\
\hline McDonald's & 1417 & 31 \\
\hline Pizza Pizza & 631 & 3 \\
\hline Pizza 73 & 102 & 21 \\
\hline Subway & 3100 & 36 \\
\hline Taco Del Mar & 45 & 20 \\
\hline Taco Time & 128 & 16 \\
\hline Tim Hortons & 4000 & 25 \\
\hline
\end{tabular}




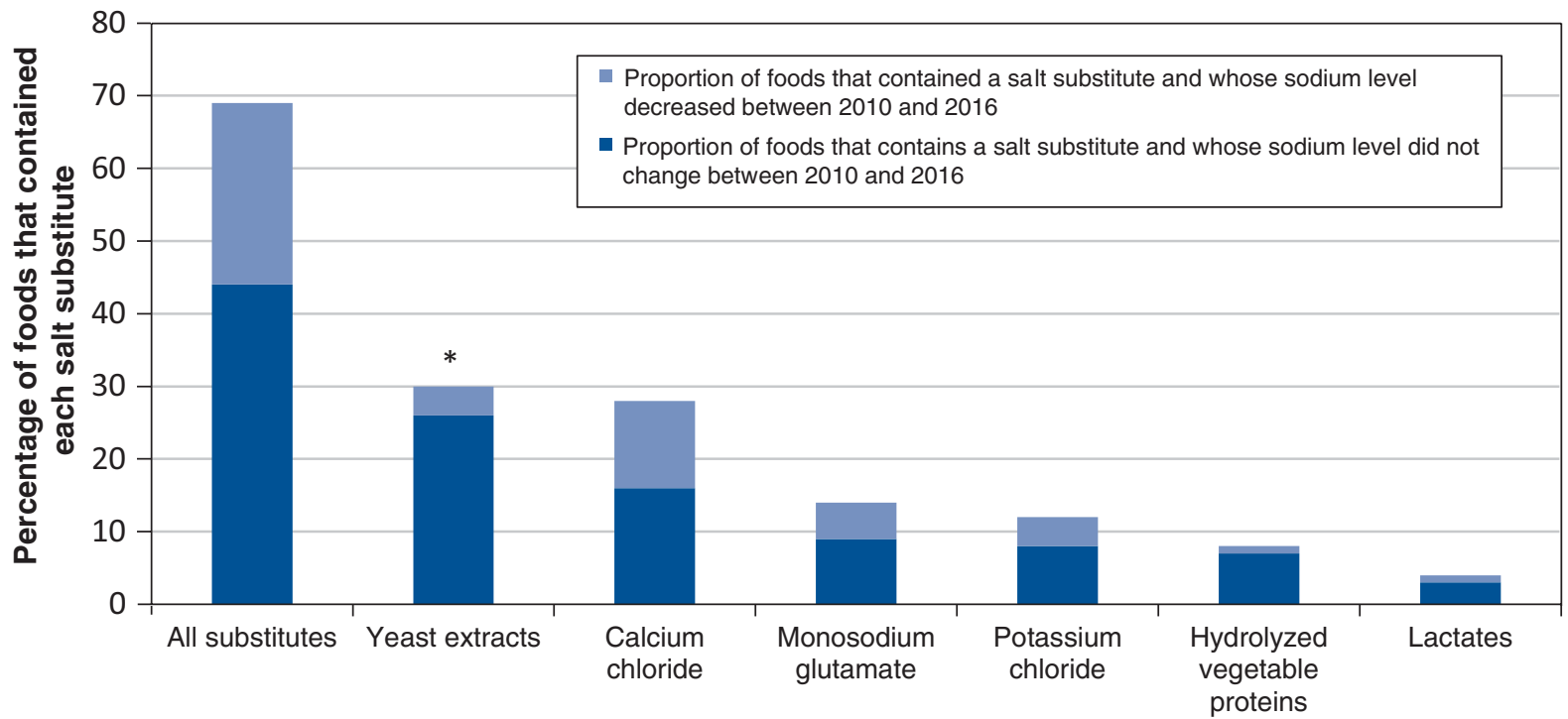

Salt substitutes/enhancers

Figure 2: Percentage of fast-food items $(n=222)$ that contained each salt substitute/enhancer and comparison of the proportion of foods that decreased $(n=140)$ and did not decrease $(n=82)$ in sodium per serving. Salt substitutes were identified using Appendix D in Strategies to Reduce Sodium Intake in the United States published by the Institute of Medicine. ${ }^{12}{ }^{*} p<0.001$ for $\chi^{2}$ test comparing the association between the presence of a particular salt substitute/enhancer in a food and the likelihood that the sodium level (mg/serving) in that food decreased between 2010 and 2016.

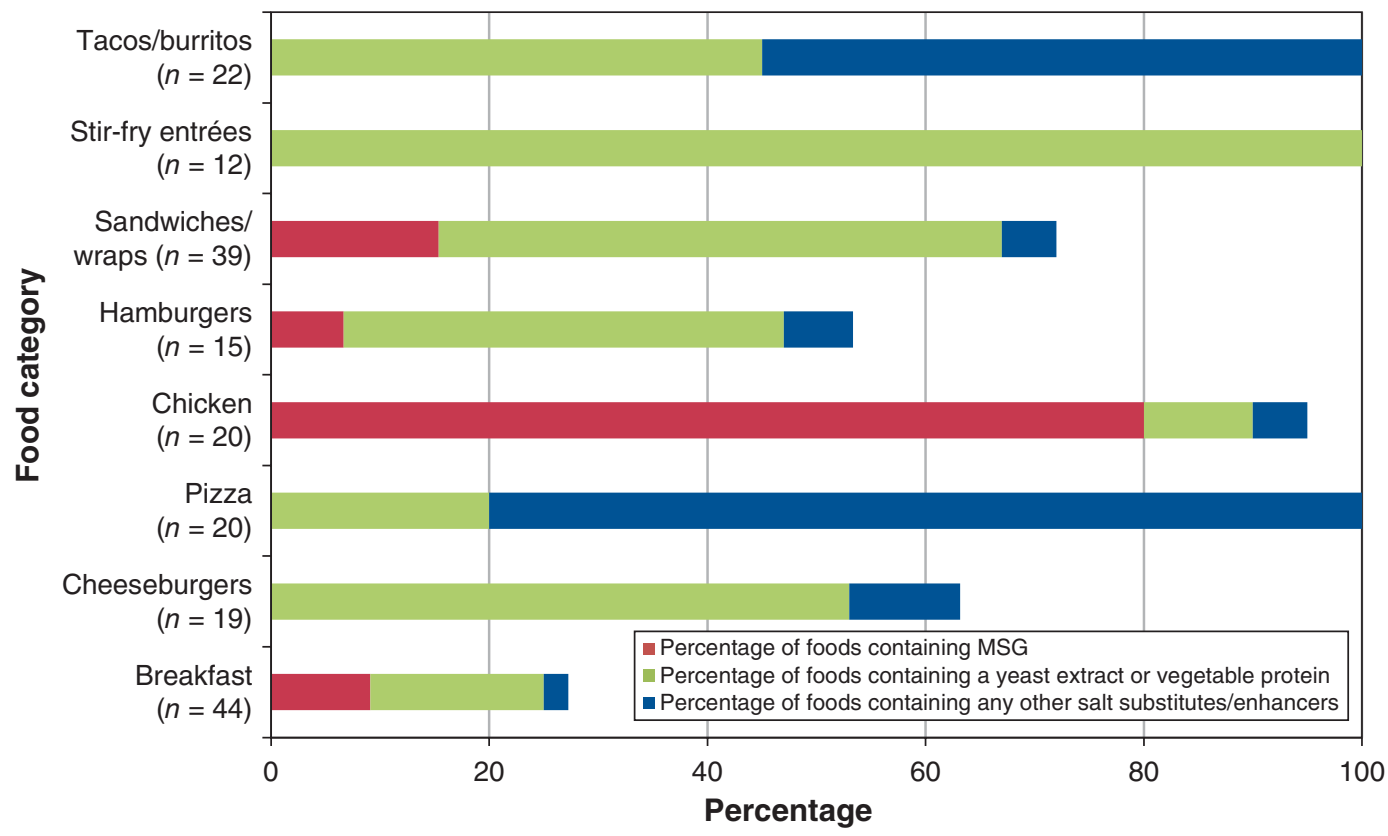

Figure 3: Proportion of fast-food items that contained salt substitutes/enhancers $(n=191)$, by food category and type of salt substitute/ enhancer. Yeast extracts and hydrolyzed vegetable proteins "often contain MSG" according to the Strategies to Reduce Sodium Intake in the United States report published by the Institute of Medicine. ${ }^{12}$ The following categories were not included in this figure because their sample size was less than 10: hot dogs $(n=2)$, sushi $(n=1)$ kids' meals $(n=3)$, fries $(n=4)$, poutine $(n=1)$, salad entrées $(n=5)$, soup $(n=9)$ and other side dishes $(n=6)$. Note: MSG $=$ monosodium glutamate . 


\section{Results}

The analysis included a total 222 foods (measured across 3 time points) from 12 of the leading fast-food restaurants in Canada (Table 1). The sample encompassed $84 \%$ of outlets from the top 10 restaurant chains (including sit-down chains) in Canada. Our data set included 11331 outlets, representing $39 \%$ of all chain-restaurant outlets across Canada.

\section{Prevalence of salt substitutes/enhancers}

Sixty-nine percent of foods contained a salt substitute/ enhancer. Yeast extracts were the most common salt substitute/enhancer, being found in 30\% of foods (Figure 2), followed by calcium chloride (in $28 \%$ of foods), monosodium glutamate (in $14 \%$ of foods), potassium chloride (in $12 \%$ of foods), hydrolyzed vegetable proteins (in $8 \%$ of foods) and lactates (in $4 \%$ of foods).

Salt substitutes/enhancers were found in every restaurant chain $(n=12)$ for which ingredient data were available. More than $50 \%$ of chicken dishes, cheeseburgers and sandwiches/ wraps (often chicken and turkey sandwiches) contained substitutes/enhancers, while $100 \%$ of tacos/burritos, stir-fry entrées and pizza slices contained substitutes/enhancers (Figure 3).

\section{Association between salt substitutes/enhancers and magnitude of decrease in sodium levels}

Sixty-four percent of the foods that contained a salt substitute/enhancer decreased in sodium level (measured in milligrams per serving) between 2010 and 2016. The sodium level of foods that contained a salt substitute/enhancer decreased by a significantly higher amount $(190 \pm 42 \mathrm{mg} /$ serving) than the sodium level of foods that did not contain a salt substitute/enhancer (40 $\pm 17 \mathrm{mg} /$ serving, $p<0.001$ ) (Figure 4). This trend was seen in all analyzable food categories, and the difference was significant in hamburgers and cheeseburgers $(p<0.001)$.

\section{Glutamate-containing substitutes/enhancers}

Salt substitutes/enhancers that contain or often contain free glutamates (MSG, yeast extracts and hydrolyzed vegetable proteins) were found in $53 \%$ of foods. Seventy percent of

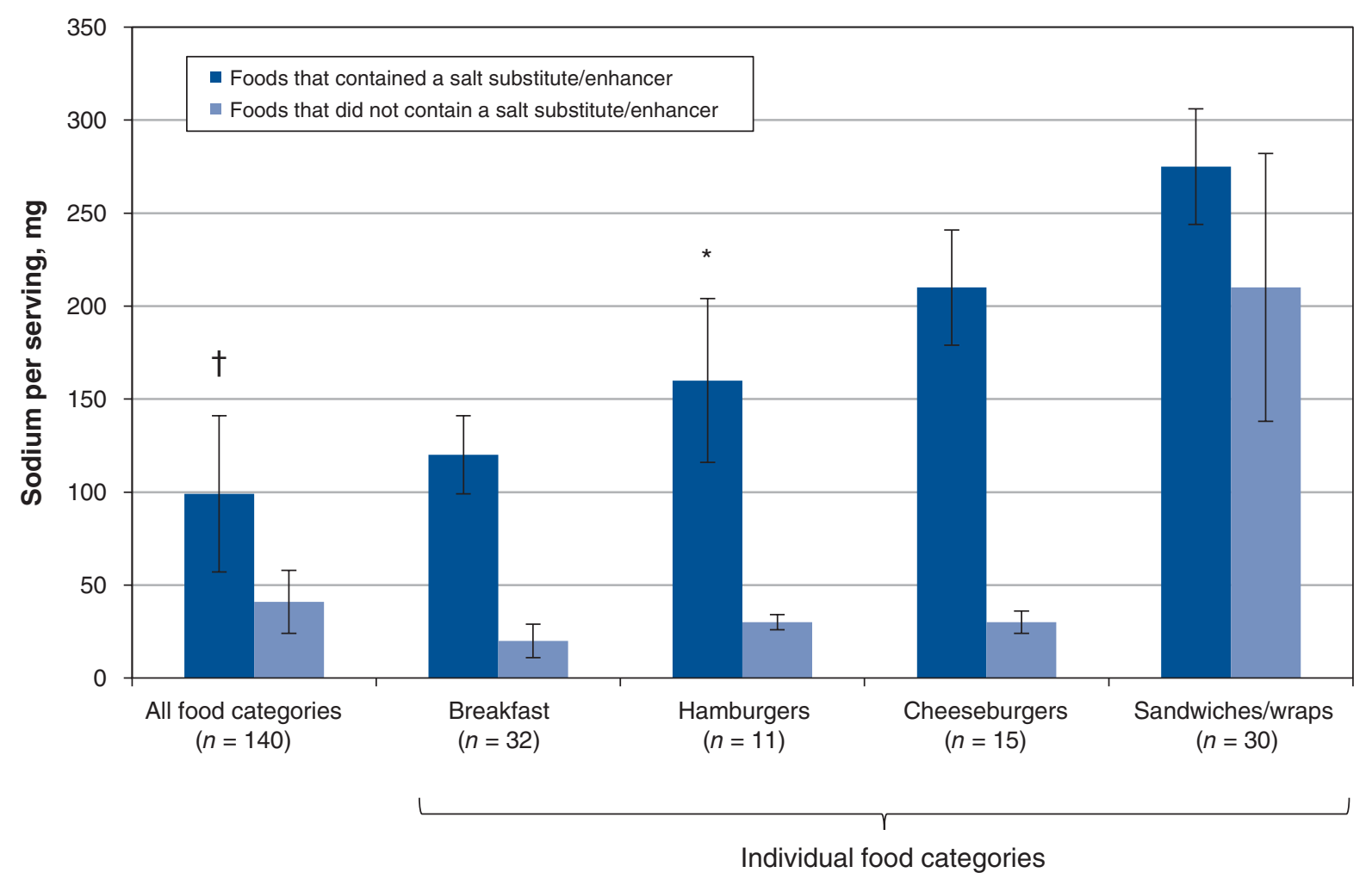

Figure 4: Magnitude of decrease in sodium (mg/serving) among fast-food items whose sodium level decreased $(n=140)$. Values are compared for foods in this group that contained a salt substitute/enhancer $(n=99)$ and foods that did not contain a salt substitute/enhancer $(n=41)$. Bars represent median \pm standard error. * $p=0.01, \dagger p<0.001$, non-parametric Wilcoxon signed-rank tests. "All food categories" includes breakfast items, cheeseburgers, chicken entrées, hot dogs, hamburgers, kids' meals, fries, pizza, poutine, salad entrées with meat, sandwiches/wraps, mashed potatoes, rice, soup and tacos/burritos. Only categories with more than 10 foods are presented individually in this figure. Although the overall study included 222 foods, only 140 foods are represented in this figure because it depicts the analysis only of foods whose sodium level decreased. 
foods that had a glutamate-containing enhancer decreased in sodium between 2010 and 2016. Furthermore, foods that had glutamate-containing enhancers were significantly more likely to have decreased in sodium $(p=0.0345)$ than foods that did not have glutamate-containing enhancers. Foods with glutamate-containing enhancers had a significantly higher magnitude of decrease $(190 \pm 39 \mathrm{mg} / \mathrm{serving})$ than foods that did not have glutamate-containing enhancers $(60 \pm$ $51 \mathrm{mg} /$ serving, $p<0.001)$.

Glutamate-containing enhancers were found in all but one restaurants that provided ingredient information. Eighty percent of chicken menu items (including battered/fried chicken and breaded chicken strips) contained MSG (Figure 3).

\section{Interpretation}

Sixty-nine percent of the foods investigated in this study contained salt substitutes/enhancers in this study. Yeast extracts (which often contain free glutamate) ${ }^{12}$ were the most common salt substitutes/enhancers, being found in 30\% of foods. MSG was found in $14 \%$ of foods and was particularly prevalent in fast-food chicken products. The sodium levels in foods that contained salt substitutes/enhancers decreased significantly more than those in foods that did not contain salt substitutes/ enhancers.

MSG is considered a safe food additive; ${ }^{49}$ however, according to the International Classification of Headache Disorders, MSG (or more specifically, free glutamate) can be a causative trigger of headaches in healthy populations and especially in people who get migraine headaches. ${ }^{50}$ Glutamate is the most ubiquitous excitatory neurotransmitter in the body, ${ }^{51}$ and it has been demonstrated to play a critical role in headache pathophysiology in animal models and human studies. ${ }^{21,22,46,52-57}$ Previous studies have detected a dose-response relationship when MSG is administered at increasing levels. ${ }^{23-25}$ One study suggested that the threshold for reactivity may be $2.5 \mathrm{~g}^{23}$ and anecdotally reported that a highly seasoned restaurant meal could provide as much as $5 \mathrm{~g}$ of MSG. At this time the MSG content of restaurant foods is unknown as levels have never been formally investigated or reported. Therefore, no conclusion can be made regarding whether the current levels in fast foods have the potential to elicit symptoms.

MSG may have different effects depending on the context in which it is consumed. Evidence from animal models suggests that a spike in plasma glutamate is the mechanism by which glutamate causes symptoms. ${ }^{47,48}$ Research has shown that when MSG is consumed on its own (i.e., in a calorie-free beverage), the plasma concentration of glutamate peaks 30 minutes to 1 hour after ingestion. ${ }^{39,58}$ However, when MSG is ingested with carbohydrates, measurable plasma concentrations of glutamate are not achieved. ${ }^{59}$ Similarly, one of the largest studies of MSG concluded that symptoms are only present when large doses are ingested without food. ${ }^{24}$ However, it should be noted that other studies have detected symptoms when MSG was administered with tomato juice ${ }^{25}$ or in the context of a lunch meal. ${ }^{28}$ In the present study, MSG was found in a variety of food categories (ranging from chicken to sandwiches to soup) with varying levels of accompanying carbohydrate. Therefore, whether or not dietary glutamate consumed in the context and amounts currently found in fast-food meals can elicit symptoms is unknown.

\section{Limitations}

The small sample $(n=222)$ of foods for which ingredient information was available and the lack of longitudinal data on the prevalence of salt substitutes/enhancers before 2016 are limitations of this study. Hence, this study demonstrates an association between salt substitutes/enhancers and changes in sodium levels (per serving) but does not prove that salt substitutes/enhancers have been added to achieve sodium reductions. Restaurant foods are constantly being introduced to or removed from menus; therefore, this study only includes foods that persisted on menus between 2010 and 2016. Ingredient data were not collected in 2010 or 2013; therefore, longitudinal comparisons to prove that substitutes were added at the same time as sodium levels decreased were not possible. Ingredient data were only available for fast-food chains; therefore, it is unknown whether the findings in this study would be applicable to sit-down restaurant chains and independent restaurants. In addition, our data set only represents restaurants that provided nutrition and ingredient information online. Furthermore, the findings of this study are dependent upon the accuracy of the data provided by the establishments. The accuracy of restaurants' self-reported sodium or ingredient information has never been investigated. Research on restaurants' self-reported information on the calories in their menu items found that the information for most foods (with some exceptions) was within the margins of error deemed acceptable in food regulations; ${ }^{45}$ however, with respect to packaged foods, research in Canada showed that the sodium levels indicated in Nutrition Facts tables were consistently underreported. ${ }^{60}$ Finally, research on MSG is highly controversial. Susceptibility to MSG-related symptoms varies from person to person and depends on dosage, amount and food source. Additional research is needed to determine the exact dose of MSG and free glutamates in restaurant foods. Therefore, at this time, conclusions cannot be drawn regarding whether or not the MSG dosage currently present in restaurant foods is sufficient to elicit symptoms. Hence, the potential consequences of these findings, if any, are uncertain.

\section{Conclusion}

Salt substitutes/enhancers are prevalent in restaurant foods and may be a means by which restaurants are responding to calls to lower sodium. More research is needed to understand the implications of these findings.

\section{References}

1. Intersalt: an international study of electrolyte excretion and blood pressure. Results for 24 hour urinary sodium and potassium excretion. Intersalt Cooperative Research Group. BM7 1988;297:319-28.

2. Lopez AD, Mathers CD, Ezzati M, et al. Global and regional burden of disease and risk factors, 2001: systematic analysis of population health data. Lancet 2006;367:1747-57. 
3. Quader ZS, Zhao L, Gillespie C, et al. Sodium intake among persons aged $\geq 2$ years - United States, 2013-2014. MMWR Morb Mortal Wkly Rep 2017;66:324-238.

4. Guthrie JF, Lin BH, Frazao E. Role of food prepared away from home in the American diet, 1977-78 versus 1994-96: changes and consequences. 7 Nutr Educ Behav 2002;34:140-50.

5. Food expenditures 2015. Washington: United States Department of AgricultureEconomic Research Service; 2016. Available: http://www.ers.usda.gov/data -products/food-expenditures.aspx (accessed 2016 Jan. 2).

6. Food-away-from-home. Washington: United States Department of Agriculture; 2014. Available: www.ers.usda.gov/topics/food-choices-health/food-consumption -demand/food-away-from-home.aspx\#nutrition (accessed 2015 Jan. 4).

7. Garriguet D. Canadians' eating habits. Ottawa: Statistics Canada; 2007. Cat no 82-003-X. Available: www.statcan.gc.ca/pub/82-003-x/2006004/ article/9609-eng.htm (accessed 2015 Dec. 4).

8. Garriguet D. Nutrition: findings from the Canadian Community Health Survey Overview of Canadians' eating habits. Ottawa: Health Statistics Division, Statistics Canada; 2004.

9. Johnson CM, Angell SY, Lederer A, et al. Sodium content of lunchtime fast food purchases at major US chains. Arch Intern Med 2010;170:732-4.

10. Wu HW, Sturm R. Changes in the energy and sodium content of main entrees in US chain restaurants from 2010 to 2011. 7 Acad Nutr Diet 2014; 114:209-19.

11. Jacobson MF, Havas S, McCarter R. Changes in sodium levels in processed and restaurant foods, 2005 to 2011. FAMA Intern Med 2013;173:1285-91.

12. Institute of Medicine. Strategies to reduce sodium intake in the United States. Washington: The National Academies Press; 2010.

13. Sodium reduction strategy for Canada. Recommendations of the Canadian Sodium Working Group. Ottawa: Health Canada; 2010.

14. National salt reduction initiative: restaurant food 2016. New York: New York City Department of Health and Mental Hygiene. Available: http:// www1.nyc.gov/site/doh/health/health-topics/salt-initiative-restaurantfood. page (accessed 2016 Jan. 24).

15. Dötsch M, Busch J, Batenburg M, et al. Strategies to reduce sodium consumption: a food industry perspective. Crit Rev Food Sci Nutr 2009;49:841-51.

16. Jinap S, Hajeb P, Karim R, et al. Reduction of sodium content in spicy soups using monosodium glutamate. Food Nutr Res 2016;60:30463.

17. Sodium reduction market by ingredients (amino acids, mineral salts, yeast extracts), applications (dairy \& frozen foods, bakery \& confectionary, meat products, sauces, seasonings \& snacks) \& geography — global trends \& forecasts to 2018. Dublin (Ireland): Research and Markets; 2013.

18. Kurihara K. Glutamate: from discovery as a food flavor to role as a basic taste (umami). Am 7 Clin Nutr 2009;90:719S-22S.

19. The facts about ... sodium reduction and MSG. International Glutamate Information Service; 2017. Available: https://glutamate.org/wp-content/uploads/2017/04/ sodium_reduction_and_msg_fact_sheet.pdf (accessed 2017 Mar. 18).

20. Kwok RH. Chinese-restaurant syndrome. N Engl 7 Med 1968;278:796.

21. Baad-Hansen L, Cairns B, Ernberg M, et al. Effect of systemic monosodium glutamate (MSG) on headache and pericranial muscle sensitivity. Cephalalgia 2010;30:68-76.

22. Shimada A, Cairns BE, Vad N, et al. Headache and mechanical sensitization of human pericranial muscles after repeated intake of monosodium glutamate (MSG). 7 Headache Pain 2013;14:2.

23. Yang WH, Drouin MA, Herbert M, et al. The monosodium glutamate symptom complex: assessment in a double-blind, placebo-controlled, randomized study. 7 Allergy Clin Immunol 1997;99:757-62.

24. Geha RS, Beiser A, Ren C, et al. Multicenter, double-blind, placebo-controlled, multiple-challenge evaluation of reported reactions to monosodium glutamate. 7 Allergy Clin Immunol 2000;106:973-80.

25. Kenney RA, Tidball CS. Human susceptibility to oral monosodium L-glutamate. Am 7 Clin Nutr 1972;25:140-6.

26. Shimada A, Baad-Hansen L, Castrillon E, et al. Differential effects of repetitive oral administration of monosodium glutamate on interstitial glutamate concentration and muscle pain sensitivity [published erratum in Nutrition 2015;31:548] Nutrition 2015;31:315-23.

27. Gore ME, Salmon PR. Chinese restaurant syndrome: fact or fiction? Lancet 1980;1:251-2.

28. Zanda G, Franciosi P, Tognoni G, et al. A double blind study on the effects of monosodium glutamate in man. Biomedicine 1973;19:202-4.

29. Reif-Lehrer L. Possible significance of adverse reactions to glutamate in humans. Fed Proc 1976;35:2205-11.

30. Prawirohardjono W, Dwiprahasto I, Astuti I, et al. The administration to Indonesians of monosodium L-glutamate in Indonesian foods: an assessment of adverse reactions in a randomized double- blind, crossover, placebo-controlled study. F Nutr 2000;130(Suppl 4S):1074S-6S.

31. Bazzano G, D'Elia JA, Olson RE. Monosodium glutamate: feeding of large amounts in man and gerbils. Science 1970;169:1208-9.

32. Tarasoff L, Kelly MF. Monosodium L-glutamate: a double-blind study and review. Food Chem Toxicol 1993;31:1019-35.
33. Rosenblum I, Bradley JD, Coulston F. Single and double blind studies with oral monosodium glutamate in man. Toxicol Appl Pharmacol 1971;18:367-73.

34. Chevassus H, Renard E, Bertrand G, et al. Effects of oral monosodium (L)glutamate on insulin secretion and glucose tolerance in healthy volunteers. $\mathrm{Br}$ 7 Clin Pharmacol 2002;53:641-3.

35. Schaumburg HH, Byck R, Gerstl R, et al. Monosodium L-glutamate: its pharmacology and role in the Chinese restaurant syndrome. Science 1969;163:826-8.

36. Colman AD. Possible psychiatric reactions to monosodium glutamate. $N$ Engl 7 Med 1978;299:902.

37. Scourboutakos MJ, L'Abbe MR. Changes in sodium levels in chain restaurant foods in Canada (2010-2013): a longitudinal study. CMA7 Open 2014;2: E343-51.

38. Stegink LD, Baker GL, Filer LJ Jr. Modulating effect of Sustagen on plasma glutamate concentration in humans ingesting monosodium L-glutamate. $\mathrm{Am}$ f Clin Nutr 1983;37:194-200.

39. Stegink LD, Filer LJ Jr, Baker GL, et al. Effect of sucrose ingestion on plasma glutamate concentrations in humans administered monosodium L-glutamate. Am 7 Clin Nutr 1986;43:510-5.

40. Scourboutakos MJ, L'Abbe MR. Sodium levels in Canadian fast-food and sitdown restaurants. Can 7 Public Health 2013;104:e2-8.

41. Scourboutakos M, Scourboutakos M. Changes in sodium levels in chain restaurant foods in Canada (2010 -2013): a longitudinal study. CMA7 Open 2014;2:E343-51.

42. Scourboutakos MJ, L'Abbe MR. Restaurant menus: calories, caloric density, and serving size. Am 7 Prev Med 2012;43:249-55.

43. Monday report on retailers. Directory of restaurant and fast food chains in Canada. Toronto: Rogers Media; 2010.

44. Monosodium glutamate (MSG): questions and answers. Ottawa: Health Canada; 2008. Available: https://www.canada.ca/en/health-canada/services/ food-nutrition/food-safety/food-additives/monosodium-glutamate-questions -answers.html (accessed 2016 July 7).

45. Renton A. If MSG is so bad for you, why doesn't everyone in Asia have a headache? The Guardian [London]; 2005 July 10.

46. O'Brien M, Cairns BE. Monosodium glutamate alters the response properties of rat trigeminovascular neurons through activation of peripheral NMDA receptors. Neuroscience 2016;334:236-44.

47. Stegink LD, Shepherd JA, Brummel MC, et al. Toxicity of protein hydrolysate solutions: correlation of glutamate dose and neuronal necrosis to plasma amino acid levels in young mice. Toxicology 1974;2:285-99.

48. Takasaki Y, Matsuzawa Y, Iwata S, et al. Toxicological studies of monosdium L-glutamate in rodents: relationship between route of administration and neurotoxicity. In: Glutamic acid: advances in biochemistry and physiology. New York: Raven Press; 1979. Available: www.ajinomoto.com.my/ pdf/toxicological-studies-monosodium-l-glutamate-rodents.pdf (accessed 2017 Apr. 11).

49. Beyreuther K, Biesalski HK, Fernstrom JD, et al. Consensus meeting: monosodium glutamate - an update. Eur 7 Clin Nutr 2007;61:304-13.

50. Headache Classification Committee of the International Headache Society (IHS). In: International Classification of headache disorders - 3rd ed. 8.1.5.1 Monosodium glutamate (MSG)-induced headache. London (UK): International Headache Society; 2016. Available: https://www.ichd-3.org/8-headache-attributed-to-a-substance-or -its-withdrawal/8-1-headache-attributed-to-use-of-or-exposure-to-a-substance/8 -1-5-headache-induced-by-food-andor-additive/8-1-5-1-monosodium-glutamate -msg-induced-headache/ (accessed 2016 Nov. 3)

51. Zhou Y, Danbolt NC. Glutamate as a neurotransmitter in the healthy brain. 7 Neural Transm (Vienna) 2014; 121:799-817.

52. Cairns BE, Dong X, Mann MK, et al. Systemic administration of monosodium glutamate elevates intramuscular glutamate levels and sensitizes rat masseter muscle afferent fibers. Pain 2007;132:33-41.

53. Gazerani P, Dong X, Wang M, et al. Sensitization of rat facial cutaneous mechanoreceptors by activation of peripheral N-methyl-d-aspartate receptors. Brain Res 2010;1319:70-82.

54. Laursen JC, Cairns BE, Dong XD, et al. Glutamate dysregulation in the trigeminal ganglion: a novel mechanism for peripheral sensitization of the craniofacial region. Neuroscience 2014;256:23-35.

55. Chan K, MaassenVanDenBrink A. Glutamate receptor antagonists in the management of migraine. Drugs 2014;74:1165-76.

56. Martinez F, Castillo J, Rodriguez JR, et al. Neuroexcitatory amino acid levels in plasma and cerebrospinal fluid during migraine attacks. Cephalalgia 1993;13:89-93.

57. Cananzi AR, D'Andrea G, Perini F, et al. Platelet and plasma levels of glutamate and glutamine in migraine with and without aura. Cephalalgia 1995; $15: 132-5$.

58. Graham TE, Sgro V, Friars D, et al. Glutamate ingestion: the plasma and muscle free amino acid pools of resting humans. Am 7 Physiol Endocrinol Metab 2000;278:E83-9.

59. Geha RS, Beiser A, Ren C, et al. Review of alleged reaction to monosodium glutamate and outcome of a multicenter double-blind placebo-controlled study. 7 Nutr 2000;130(Suppl 4S):1058S-62S. 
60. Fitzpatrick L, Arcand J, L'Abbe M, et al. Accuracy of Canadian food labels for sodium content of food. Nutrients 2014;6:3326-35.

61. Giacometti T. Free and bound glutamate in natural products. In: Glutamic acid: advances in biochemistry and physiology. New York: Raven Press; 1979. Available: www.ajinomoto.com.my/pdf/free-bound-glutamate-natural-products.pdf (accessed 2017 Apr. 11).

Affiliation: Department of Nutritional Sciences, Faculty of Medicine, University of Toronto, Toronto, Ont.

Contributors: Mary Scourboutakos and Mary L'Abbé conceived and designed the study. Mary Scourboutakos, Sarah Murphy and Mary L'Abbé acquired the data. Mary Scourboutakos analyzed and interpreted the data. Mary Scourboutakos wrote the manuscript. Mary Scourboutakos, Sarah Murphy and Mary L'Abbé revised the manuscript for important intellectual content. Mary L'Abbé obtained funding and supervised the study. All of the authors gave approval of the final version for publication and agreed to be accountable for all aspects of the work.

Funding: Mary Scourboutakos was supported by a Vanier Canada Graduate Scholarship from the Canadian Institutes of Health Research. Mary L'Abbé received an Earle W. McHenry Chair unrestricted research grant from the University of Toronto. This study was also partially supported through a collaborative partnership with Public Health Ontario.

Acknowledgements: The authors owe special thanks to Tina Qutta, who assisted with data-entry checks; to Paul Corey, who provided statistical guidance; and to all of the "L'Abbé Lab Girls" for their unwavering research support and encouragement.

Supplemental information: For reviewer comments and the original submission of this manuscript, please see www.cmajopen.ca/content/6/1/ E118/suppl/DC1. 